\title{
IMF Conditionality and Programme Ownership in Developing and Emerging Economies - Implementation and Research Agenda: An Introduction to Special Issue: Symposium Part I
}

\author{
ALI M KUTAN \\ Department of Economics and Finance, School of Business, Southern Illinois \\ University, Edwardsville, IL 62026-1102, USA. E-mail: akutan@siue.edu
}

Comparative Economic Studies (2004) 46, 371-372. doi:10.1057/palgrave.ces.8100067

The impact of IMF programmes in emerging and developing economies has been extensively studied. Despite the intensive work, evidence regarding the effectiveness of IMF conditionality in developing and emerging economies seems to be mixed. Results appear to be sensitive to the countries studied and the macroeconomic variables investigated. More recently, the debate has been extended to issues such as the effectiveness of structural reforms and practicality of ownership. In addition to its traditional conditionality that targets various fiscal and monetary variables, the IMF has recently included structural reforms in conditionality and emphasised improved programme ownership. The purpose of the special issue is to contribute to the ongoing debate on the effectiveness of IMF conditionality and structural reforms, as well as the issues regarding the implementation of programme ownership in practice. This September issue represents the first part of the special issue. The March 2005 issue of CES will include Part II of this special issue.

In the first paper of this issue, Ales Buliŕ and Soojin Moon examine the impact of IMF structural conditionality on post-programme fiscal performance in developing countries during the 1990s. They compare the performance of fiscal adjustment in countries with and without structural adjustment. In countries that received IMF support, they find that there was a slight increase in revenues but a significant decline in expenditures. On the other hand, nonstructural conditionality countries experienced some increase 
in expenditures with no significant change in revenue. Overall, it is found that fiscal structural conditions do not tend to improve revenue performance during the post-programme period. Rather, fiscal performance was affected by business cycles and macroeconomic policies.

Papers by Graham Bird and Thomas D Willett, and Wolfgang Mayer and Alex Mourmouras focus on the concept of programme ownership. Bird and Willett argue that this ownership concept may have a limited operational value because it is difficult to define it precisely. They propose a narrow concept of ownership that improves the prospects for programme implementation by stressing political economy variables and making concessions about the technical designs of programmes. Mayer and Mourmouras first present an analytical work - the theory of special interest politics - which indicates a strong theoretical case for conditionality. Next, they provide a review of the literature on country ownership. They conclude that, while theory provides a strong case for conditionality, the available empirical evidence regarding its implementation is quite mixed. They emphasise the need of designing programmes that are more resilient to political and economic shocks.

The last two papers in Part I by Joseph P Joyce, and Graham Bird and Dane Rowlands provide an extensive review of the recent literature on IMF's lending programmes. Joyce's review focuses on four specific issues: (1) factors that are important to initiate a Fund-supported programme, (2) success on the implementation of programmes, (3) economic impact of Fundsupported policies, and (4) the reaction of capital markets to IMF programme news. Joyce also outlines some new directions for further research, including factors leading to the partial completion of programmes as well as the importance of moral hazard considerations leading to currency crises. Bird and Rowlands review the literature on the catalytic effect of IMF lending, which suggests that IMF financing may attract additional funding from other sources as Fund programmes signal credibility about countries' economic policies to investors. They argue that the accumulated evidence so far does not support the catalytic effect hypothesis. The authors suggest that there is an emerging need of designing alternative ways by which IMF policies may increase capital flows to countries with a Fund programme. They believe that this issue will become increasingly more important as the nature of capital inflows changes over time. Hence, the authors suggest that the IMF needs to undertake a more 'radical action' to improve access to much needed foreign capital in developing and emerging countries. 